\title{
Implante orbital misto para reconstrução de cavidade anoftálmica: relato de caso
}

\author{
Miscellaneous orbital implant for anophthalmic cavity reconstruction surgery: \\ case report
}

Davi Araf ${ }^{1}$

Omar Massayoshi Assae ${ }^{2}$

Rodrigo Vuono de Brito ${ }^{3}$

Guido Aquino Jr. ${ }^{4}$

Tania Aleksandra Gomes da Silva ${ }^{5}$

\section{RESUMO}

Apresentamos um novo modelo de implante orbital unindo o baixo custo da esfera de luxite (PMMA) com as vantagens da utilização do polietileno poroso $\left(\right.$ Porex $\left.^{\circledR}\right)$. O novo modelo consiste de uma esfera de luxite na qual em sua face anterior foi colocado um recorte de dura-máter do mesmo diâmetro da esfera, e na face posterior um recorte de polietileno poroso foi anexado à esfera de luxite por meio de cola (Cianoacrilato estéril). A dura-máter foi fixada ao polietileno poroso por meio de suturas com fio nylon monofilamentar 6.0. Foi realizada cirurgia em um paciente que já havia tido extrusão anterior do implante em um dos olhos, sendo este avaliado em seu pós-operatório imediato, $7^{\circ}$, $15^{\circ}, 30^{\circ}$ dia, além de 3 e 6 meses de pós-operatório quando foi avaliado por meio de tomografia computadorizada. Observou-se bom resultado cosmético, de mobilidade e de volume após adaptação da prótese escleral, não havendo nenhum sinal de infecção, migração ou extrusão do implante até o momento. $\mathrm{O}$ caso nos mostrou ser possível a utilização de um implante orbital mais acessível economicamente com resultados semelhantes aos dos implantes biointegráveis.

Descritores: Enucleação ocular; Anoftalmia/cirurgia; Implantes orbitários; Porosidade; Polietilenos; Géis; Coelhos; Animais

\section{INTRODUCÃO}

Implantes orbitais esféricos são utilizados para reposição do conteúdo da órbita em cavidades anoftálmicas ${ }^{(1)}$.

Está comprovado que a cavidade orbital mantém a sua integridade anatômica e funcional quando possui um bulbo ocular ou implante que o substitua adequadamente em forma e volume ${ }^{(2)}$.

Vários enxertos de tecidos, como osso, gordura, derme e dermogorduroso têm sido utilizados, bem como a inclusão de materiais aloplásticos e orgânicos, principalmente acrílico, silicone, hidroxiapatita e polietileno poroso. A alta incidência de extrusão destes materiais tem levado a uma maior pesquisa e escolha por aqueles que apresentem maior biocompatibilidade. Outros fatores que têm reduzido o índice de extrusão são um melhor posicionamento e fixação destes implantes e, principalmente, a cobertura anterior com outros materiais e tecidos ${ }^{(3)}$.

Existem diversos tipos e modelos de implantes orbitais. O material ideal para confecção de esferas ainda não é conhecido. Sabe-se que deve ser biocompatível, não alergênico e não cancerígeno. Além disso, é necessário que tenha preço acessível para ser utilizado em larga escala ${ }^{(4)}$. 
Dentre os diversos tipos de implantes sugeridos, a esfera de Mules de acrílico ainda permanece como mais utilizada, porém cresceu a preferência pelos implantes integrados de hidroxiapatita natural desenvolvido por alguns autores ${ }^{(5)}$ e por seus sucedâneos de biocerâmica ${ }^{(6)}$ ou de polietileno poroso ${ }^{(7)}$; estes possibilitam maior mobilidade da prótese e apresentam um menor índice de rejeição devido à vascularização completa do implante que se realiza por dentro de seus canais naturalmente interligados ${ }^{(2)}$.

O objetivo deste trabalho é o de apresentar um novo modelo de implante orbital unindo o baixo custo da esfera de luxite com as vantagens da utilização do polietileno poroso $\left(\right.$ Porex $\left.^{\circledR}\right)$.

\section{RELATO DO CASO}

Paciente de 26 anos, feminino, branca, procedente de Sorocaba (SP) com queixa de que a prótese não se mantinha na cavidade há anos.

Refere ter feito cirurgia de retirada do bulbo ocular direito aos 4 meses de idade devido a tumor (sic).

Ao exame a paciente apresentava cavidade anoftálmica direita profunda sem implante.

Em 11-11-05 foi realizada cirurgia de reconstrução de cavidade anoftálmica com introdução de esfera de luxite (implante secundário). Após um mês de pós-operatório a paciente apresentou extrusão da esfera.

Em 15-07-06 foi realizada nova cirurgia onde foi introduzido um novo modelo de implante. Este novo modelo consiste na utilização de esfera de luxite com posicionamento na face anterior de recorte de dura-máter anexada com fio nylon monofilamentar 6.0 e na face posterior com polietileno poroso fixado com cola (cianoacrilato estéril) (Figura 1A).

O recorte de polietileno poroso foi retirado de resíduo de material utilizado em cirurgia de reconstrução de parede inferior da órbita por fratura, tendo sido esterilizado em óxido de etileno. A paciente estava ciente da utilização deste material e consentiu com o procedimento.

A paciente foi avaliada em seu pós-operatório imediato, $7^{\circ}$ dia, $15^{\circ}$ dia, $30^{\circ}$ dia, 3 e 6 meses de pós-operatório sendo então avaliada também por meio de tomografia computadorizada (TC) de órbita com cortes coronais. (Figura 1B).

\section{DISCUSSÃO}

Os principais objetivos na reconstrução de cavidade anoftálmica são a reposição do volume perdido pela retirada do bulbo ocular e a possibilidade de utilização de uma prótese estética fina e leve, que apresente uma mobilidade o mais semelhante possível de um olho normal ${ }^{(3)}$.

Quanto ao material utilizado, os implantes podem ser classificados em orgânicos (enxerto dermoadiposo, retalho de músculo temporal) e por aloplásticos (esferas de polimetilmetacrilato, silicone, vidro, metal, hidroxiapatita e polietileno de alta densidade) ${ }^{(8)}$.
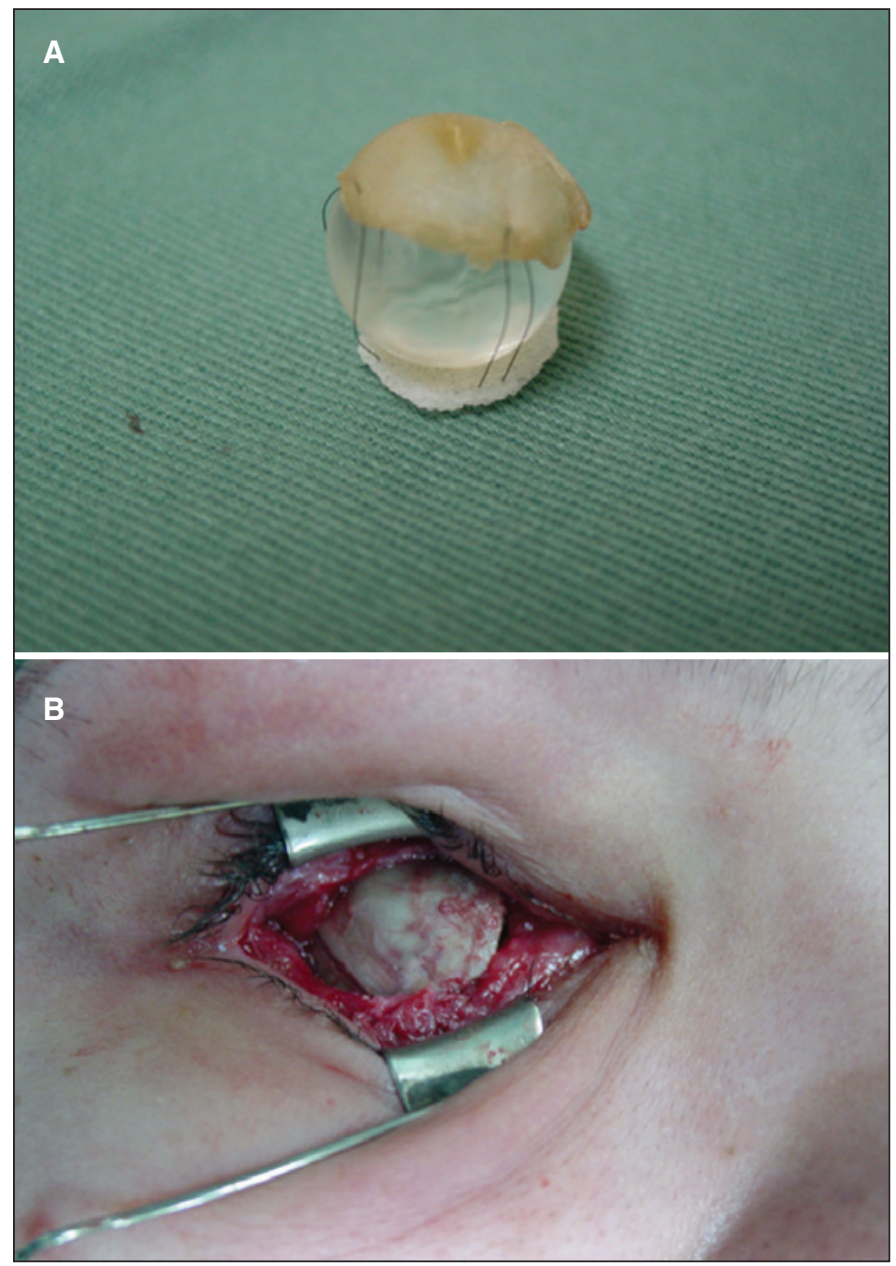

Figura 1 - A) Implante orbital misto; B) Aspecto do implante ao ser introduzido na cavidade

As diferenças no formato e no material têm como propósito tentar melhorar a mobilidade da prótese, o aspecto cosmético e minimizar as complicações ${ }^{(8)}$.

O luxite (polimetilmetacrilato) é um material não-biointegrável, de baixo custo, que vem sendo utilizado desde os anos $40^{(9)}$.

Em 1989 o Food and Drug Administration (FDA) aprovou o uso dos implantes de hidroxiapatita. Estes implantes permitem um crescimento de tecido fibrovascular que os "integra" na estrutura orbital, facilitando uma melhor mobilidade das próteses oculares e uma menor taxa de complicações pós-operatórias, tais como a migração ou extrusão do implante. Logo surgiram os implantes de polietileno poroso $\left(\operatorname{Porex}^{\circledR}\right.$ ), mais barato que a hidroxiapatita e mais resistente ${ }^{(9)}$.

Os implantes integrados sofrem vascularização progressiva, resultando na integração entre esfera e hospedeiro. A integração dos implantes com o hospedeiro pode ser atestada pelo grau de vascularização das esferas, comprovado por meio de métodos histológicos ou exames de imagem, como a tomografia computadorizada, a ressonância magnética ou a ultrassonografia ${ }^{(1)}$. 
Estudo anterior já demonstrou que o uso da cola em reconstruções de cavidade anoftálmica não ocasiona nenhum efeito deletério aos tecidos próximos ao local da aplicação, sinal de que o cianoacrilato é inerte e não provoca danos aos tecidos que o recebem ${ }^{(10)}$.

Obtivemos um bom resultado cosmético, de mobilidade e de volume após adaptação da prótese escleral (Figura 2A).

A tomografia computadorizada realizada após 6 meses da cirurgia mostrou implante bem posicionado na órbita, não apresentando nenhum sinal de infecção, migração ou extrusão do implante (Figura 2B).

A cirurgia mostrou ser possível a utilização de implante mais acessível economicamente com resultado semelhante ao dos implantes biointegráveis.

A paciente teve significativa melhora do estado emocional, fato já bem comprovado por estudos anteriores.
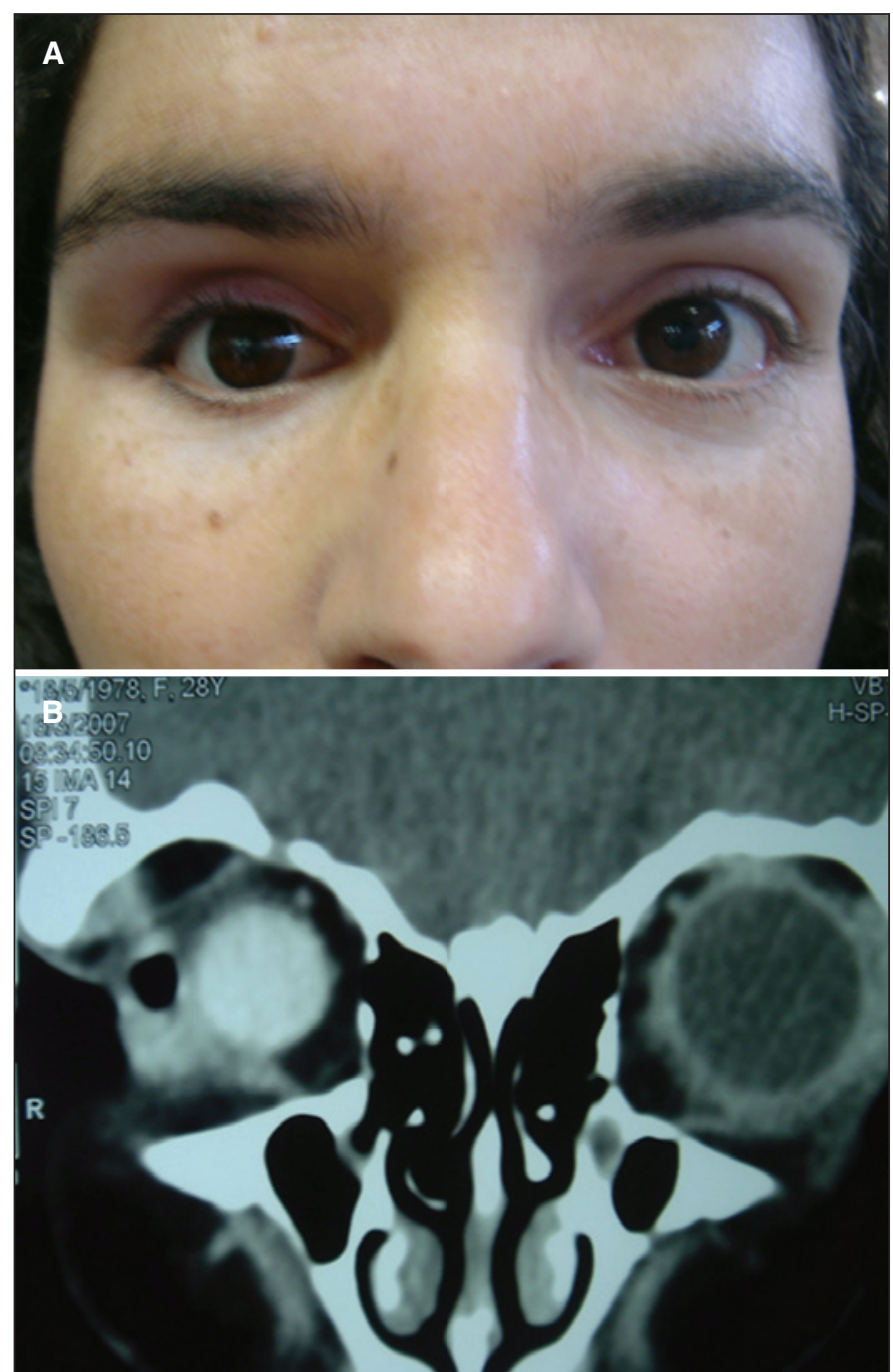

Figura 2 - A) Paciente após adaptação da prótese ocular; B) TC corte axial mostrando esfera e polietileno poroso bem adaptados
Poderá se tornar uma alternativa para as cirurgias de reconstrução de cavidade anoftálmica, principalmente em serviços públicos e para pacientes de baixa renda.

\section{ABSTRACT}

A new model of orbital implant, matching the low cost of acrylic implants (PMMA) with the advantages of medpor $\left(\right.$ Pore $\left.^{\circledR}\right)$ is presented herein. The new implant model consists of a PMMA implant with a dura mater scrap adhered on its anterior face of the same diameter of the acrylic implant and a medpor snip adhered on its posterior face by sterile cyanoacrylate. Dura mater was fixed to medpor with 6.0 mononylon. One patient who presented previous extrusion of the implant was submited to surgery and was evaluated on the $1^{\text {st }}, 7^{\text {th }}, 15^{\text {th }}, 30^{\text {th }}$ postoperative days, and 3 and 6 months after surgery when a computed tomography was performed. A good cosmetic, mobility and volume result was noted after an escleral prosthesis was adapted, with no infection, migration or extrusion of the implant until this moment. This case showed us that it is possible to use a more economic implant model with the same results of medpor (Porex $\left.{ }^{\circledR}\right)$.

Keywords: Eye enucleation; Anophthalmos/surgery; Orbital implants; Porosity; Polyethylenes; Gels; Rabbits; Animals

\section{REFERÊNCIAS}

1. Ferraz LC, Schellini SA, Wludarski SL, Padovani CR. [Gel and porous polyethyulene implants in the rabbit anophthalmic cavity]. Arq Bras Oftalmol. [Internet]. 2006[citado 2008 Jun 12];69(3):305-8. Portuguese. Disponível em: http://www.scielo.br/pdf/abo/v69n3/30777.pdf

2. Soares EJC, Moura EM, Gonçalves JOR. Cirurgia Plástica Ocular. São Paulo: Roc; 1997. Cavidades anoftálmicas. p.327-72.

3. Sebastiá R, Lessa S, Flores EE. Reconstrução da cavidade anoftálmica com implante esférico revestido de enxerto autólogo de fáscia lata. Rev Bras Oftalmol. 2000;59(2):132-43

4. Schellini SA, Hoyama E, Padovani CR, Ferreira VL, Roça R. Complicações com uso de esferas não integráveis e integráveis na reconstrução da cavidade anoftálmica. Arq Bras Oftalmol. [Internet]. 2000[citado 2008 Jul 18];63(3):175-8. Disponível em: http://www.scielo.br/pdf/abo/v63n3/13580.pdf

5. Perry AC. Integrated orbital implants. Adv Ophthalmic Plast Reconstr Surg 1990;8:75-81.

6. Soares EJC, França VP, Wykrota L, Stumpf S. Clinical evaluation of a new Bioceramic ophthalmic implant. Orbit 1995;14:137-46.

7. Ashworth JL, Rhatigan M, Sampath R, Brammar R, Sunderland S, Leatherbarrow B. The hydroxyapatite orbital implant: a prospective study. Eye (Lond). 1996;10 (Pt 1):29-37.

8. Matayoshi S, Forno EA, Moura EM. Manual de cirurgia plástica ocular. São Paulo: Roca; 2004. Evisceração e Enucleação. p.271-86. (Série Oftalmologia USP).

9. Pina AP, Dias R. Implantes orbitários e próteses oculares, sua história e evolução. Acta Oftalmol. 2003;13:33-6.

10. Ferraz LC, Schellini AS, Wludarski SL, Padovani CR, Muller S. [2-octylcynanocrylate in rabbit anophthalmic cavity reconstruction] Arq Bras Oftalmol [Internet]. 2007[citado 2008 Set 15];70(2):221-8. Portuguese. Disponível em: http://www.scielo.br/pdf/abo/v70n2/06.pdf 